\title{
Wenn die Geborgenheit zerstört wird
}

\author{
Die Zahl der Einbrüche nimmt stetig zu. Im Rahmen einer Befragung von jeweils 500 \\ Betroffenen aus fünf deutschen Großstädten hat das Kriminologische Forschungsinstitut \\ Niedersachsen e.V. (KFN) u. a. die psychischen Folgen von Wohnungseinbrüchen untersucht. \\ Wir sprachen mit Prof. Christian Pfeiffer über die Auswirkungen solcher Erfahrungen.
}

\section{$?$}

Prof. Dr. Christian Pfeiffer ehem. Direktor Kriminologisches Forschungsinstitut Niedersachsen e. V. Hannover

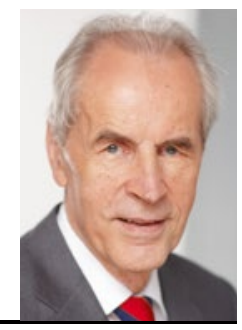

MMW: Welche psychischen Folgen zeigen sich bei den Opfern nach einem Wohnungseinbruch?

Pfeiffer: Am häufigsten berichteten die Befragten, dass sie sich nach dem Ereignis in ihrer gewohnten Umgebung unsicher fühlten. Die Wohnung ist ja etwas, das wir als Geborgenheits- und Rückzugsecke für unser psychisches Gleichgewicht brauchen. Bei drei Viertel der Betroffenen war dieses Gleichgewicht gestört, bei rund $29 \%$ nur in den ersten acht Wochen, $46 \%$ hatten auch nach einem Jahr noch Probleme, in das alte Grundwohlgefühl zurückzufinden. Gestresst und sehr angespannt waren 38\% innerhalb der ersten vier Wochen, bei $23 \%$ bestanden diese Symptome längerfristig. Rund 40\% litten unter Schlafstörungen, die Hälfte davon auch noch nach einem Jahr. Ein Viertel der Einbruchsopfer berichtete über Albträume, die jeden Zweiten noch zwölf Monate später verfolgten.

\section{MMW: Haben Sie auch posttraumati-} sche Belastungsstörungen festgestellt? Pfeiffer: Ja, zum Glück nur bei einem kleinen Teil von unter 3\%. Betroffen sind vor allem Menschen, die schon durch andere Lebensereignisse vorbelastet sind.
MMW: Leiden bestimmte Personengruppen besonders unter den Folgen eines Einbruchs?

Pfeiffer: Die am stärksten gefährdete Gruppe sind alleinstehende Frauen. Manche Frauen empfinden das Durchwühlen ihrer Kleider als so grässlich, dass sie diese nicht mehr anziehen wollen, nachdem der Täter sie in der Hand hatte. Der Einbruch in die Intimsphäre scheint bei ihnen eine große Rolle zu spielen. Auch langfristige Effekte werden besonders oft von Frauen geschildert. Ähnlich schwer belastet sind auch ältere Menschen.

MMW: Welche praktischen Konsequenzen ziehen die Opfer aus einem Einbruchserlebnis?

Pfeiffer: Die Zahl derer, die anschließend große Anstrengungen unternehmen, um das Risiko eines Einbruchs zu verringern, ist beachtlich. Nachträglich werden die Fenster besser gesichert, die Tür bekommt ein neues Schloss, das nicht so leicht aufzubrechen ist, usw. Die

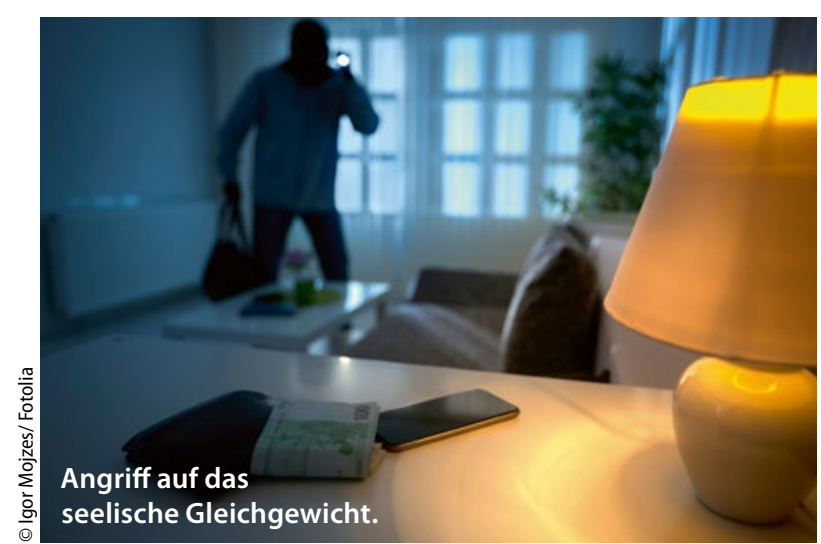

Menschen sind also durch Schaden wirklich klug geworden. 25\% der Opfer haben der Umfrage zufolge einen Umzug erwogen, $10 \%$ haben ihn in die Tat umgesetzt. Das ist eindeutig eine Lösung im Sinne des Geborgenheitsgefühls. Oft erfolgt der Umzug in eine Umgebung, in der das Einbruchsrisiko niedriger ist. Frauen äußern am häufigsten den Wunsch, in ein Hochhaus zu ziehen, wo man gegen Einbruch besser gesichert ist.

MMW: Nach welchem Zeitraum sollten Betroffene bei anhaltender Symptomatik professionelle Hilfe suchen? Pfeiffer: Wenn die Schlafstörungen auch noch drei Monate nach der Tat bestehen und die Albträume nicht aufhören, sind dies Hinweise darauf, dass man sich therapeutische Hilfe suchen sollte. Vor allem dann, wenn auch das Reden mit Freunden, Nachbarn oder Familienangehörigen nicht geholfen hat und das Grundgefühl der Geborgenheit noch immer massiv beeinflusst ist. Die Forschung zeigt, dass psychische Belastungen, die durch einmalige Ereignisse ausgelöst werden, im Gegensatz $\mathrm{zu}$ immer wiederkehrenden Belastungen, etwa im familiären Bereich, besonders gut therapierbar sind.

Interview:

Dr. Christine Starostzik 